\title{
Relação entre gênero no conselho de administração e no comitê de auditoria com o audit delay
}

\author{
Relationship between gender in the board of directors and the audit committee with the \\ audit delay
}

Relación entre el género en el consejo de administración y en el comité de auditoría y la demora en la auditoría

\section{Luís Antonio Lay}

Mestre em Ciências Contábeis pelo Programa de Pós-Graduação em Ciências Contábeis da Universidade Regional de Blumenau (FURB)

Professor Substituto da Universidade do Contestado (UnC - Campus Mafra)

Endereço: Av. Presidente Nereu Ramos, 1071 - Jardim do Moinho.

CEP: 89300-000 - Mafra/SC - Brasil

E-mail: luisantoniolay@gmail.com

Telefone: (47) 3641-5500

\section{Michele Gonçalves}

Mestre em Ciências Contábeis pelo Programa de Pós-Graduação em Ciências Contábeis da Universidade Regional de Blumenau (FURB)

Professora Substituta da Universidade do Estado de Santa Catarina (UDESC)

Endereço: Rua Antônio da Veiga, 140 - Victor Konder.

CEP: 89012-900 - Blumenau/SC - Brasil

E-mail: michele_goncalves36@yahoo.com.br

Telefone: (47) 3321-9000

\section{Paulo Roberto da Cunha}

Doutor em Ciências Contábeis e Administração pelo Programa de Pós-Graduação em Ciências Contábeis da Universidade Regional de Blumenau (FURB)

Professor no Programa de Pós-Graduação em Ciências Contábeis da FURB e da Universidade do Estado de Santa Catarina (UDESC)

Endereço: Rua Antônio da Veiga, 140 - Victor Konder.

CEP: 89012-900 - Blumenau/SC - Brasil

E-mail: pauloccsa@furb.br

Telefone: (47) 3321-0565

Artigo recebido em 25/12/2016. Revisado por pares em 16/02/2017. Reformulado em 07/10/2017. Recomendado para publicação em 22/09/2017 por Carlos Eduardo Facin Lavarda (Editor-Chefe). Publicado em 31/12/2017. 


\title{
Resumo
}

O estudo verificou a relação entre o gênero na composição do conselho de administração e do comitê de auditoria com o audit delay. A amostra da pesquisa compreende 75 empresas pertencentes ao índice IBrX 100. As variáveis pesquisadas foram a presença da mulher no conselho de administração e no comitê de auditoria, tamanho do comitê de auditoria, independência do conselho de administração, expertise, tamanho da empresa, endividamento, tamanho da firma de auditoria e honorários de auditoria. A coleta de dados ocorreu no Formulário de Referência e na base de dados Economática ${ }^{\circledR}$. Para análise dos dados utilizou-se estatística descritiva e regressão linear múltipla por meio do software SPSS ${ }^{\circledR}$. Verificou-se que a presença da mulher é maior no conselho de administração que no comitê de auditoria, havendo uma pequena parcela de membros com expertise. Os resultados evidenciaram que a presença da mulher no comitê de auditoria possui associação negativa e significante com o audit delay, ou seja, a presença da mulher neste órgão de governança corporativa contribui para a redução do prazo de divulgação do relatório do auditor. Ainda, o tamanho da empresa e a independência do conselho de administração também se mostraram significantes no modelo final em relação ao audit delay. A presença da mulher no conselho de administração não apresentou significância com o audit delay.

Palavras-chave: Gênero; Conselho de administração; Comitê de auditoria; Audit Delay

\begin{abstract}
The study verified the relationship between the gender in the composition of the board of directors and the audit committee with the audit delay. The survey sample consisted of 75 companies belonging to the $I B r X 100$ index. The variables surveyed were the presence of women on the board of directors and on the audit committee, size of the audit committee, independence of the board of directors, expertise, company size, debt, size of the audit firm and audit fees. Data collection took place in the Reference Form and the Economática ${ }^{\circledR}$ database. Data analysis was performed using descriptive statistics and multiple linear regression using SPSS ${ }^{\circledR}$ software. It was found that the presence of women is greater on the board than on the audit committee, with a small number of experienced members. The results showed that the presence of women on the audit committee has a negative and significant association with the audit delay, that is, the presence of women in this organism of corporate governance contributes to the reduction of the period of disclosure of the auditor's report. In addition, the size of the company and the independence of the board of directors were also important in the final model in relation to the audit delay. The presence of women on the board of directors was not significant with the delay in the audit.
\end{abstract} Keywords: Gender; Board of directors; Audit committee; Audit delay

\section{Resumen}

Este estudio verificó la relación entre el género en la composición del consejo de administración y del comité de auditoría con la demora en la auditoría. La muestra de la investigación comprendió 75 empresas pertenecientes al índice IBrX 100. Las variables seleccionadas fueron la presencia de mujeres en el consejo de administración y en el comité de auditoría, tamaño del comité de auditoría, independencia del consejo de administración, experiencia, tamaño de la empresa, endeudamiento, tamaño de la empresa de auditoría y honorarios de auditoría. La recolección de datos se produjo usando el formulario de referencia y la base de datos Economática ${ }^{\circledR}$. El análisis de datos se realizó mediante estadistica descriptiva y regresión lineal múltiple usando el software SPSS ${ }^{\circledR}$. Se verificó que la presencia de la mujer es mayor en el consejo de administración que en el comité de auditoría, con un pequeño grupo de miembros con experiencia. Los resultados mostraron que la presencia de la mujer en el comité de auditoría tiene una asociación negativa y significativa con la demora en la auditoría, o sea, la presencia de la mujer en este órgano de gobernanza corporativa contribuye a la reducción del plazo de divulgación del informe de auditoría. Además, el tamaño de la empresa y la independencia del consejo de administración también se mostraron significativos en el modelo final en relación con la demora en la auditoría. La presencia de la mujer en el consejo de administración no fue significativa en la demora en la auditoría.

Palabras clave: Género; Consejo de administración; Comité de auditoría; Demora en la auditoría 


\section{Introdução}

O Instituto Brasileiro de Governança Corporativa (IBGC, 2016a) descreve as características e atribuições do Conselho de Administração e destaca a responsabilidade pela definição de estratégias, orientação, monitoramento dos planos de ação organizacional, além, de ter ações referentes ao desenvolvimento da Governança Corporativa brasileira.

Assim, o Conselho de Administração tem como uma de suas principais funções a fiscalização e monitoramento de atividades organizacionais, inclusive sobre a atuação real do diretor da empresa, verificando e controlando sua atuação, para que conflitos de interesses entre a gestão e acionistas sejam minimizados (BANGE; MAZZEO, 2004).

As organizações modernas, incumbem aos conselhos de administração, o direito de tomar as decisões relacionadas à empresa, e este grupo, também por delegação dos acionistas, repassa aos gestores esse poder. Porém, em contrapartida, demanda-se a prestação de contas e implementa-se o acompanhamento sistemático das principais decisões que estão sendo realizadas na empresa (MARTINEZ, 2010).

O componente crítico, que auxilia o Conselho de Administração sobre a qualidade dos demonstrativos financeiros, bem como controles organizacionais internos para garantir a confiabilidade dos dados divulgados e identificações de riscos é o Comitê de Auditoria, que ajuda a garantir práticas de gestão de acordo com as normas contábeis exigidas (IBGC, 2015).

Conforme Thiruvadi e Huang (2011), os membros do comitê de auditoria são responsáveis por supervisionar o trabalho dos auditores, e também, a ligação com os gestores e auditores, a fim de melhorar a qualidade dos relatórios financeiros da empresa. Os autores ainda afirmam que se o comitê de auditoria é bastante eficaz, não só a gestão será menos agressiva, como também o auditor será mais conservador.

De maneira a determinar as melhores formas de gestão com a finalidade de realizar decisões mais assertivas e maximizar constantemente os resultados, alguns estudos estão sendo realizados para verificar se o gênero pode ou não afetar o desenvolvimento organizacional e outras atribuições do diretor (ROST; OSTERLOH, 2009; HUANG; HUANG; LEE, 2014; MONTENEGRO; BRÁS, 2015; SULTANA, 2015). Alguns estudos que relacionaram os gêneros, possibilitaram obter evidências de que a presença de indivíduos do sexo feminino na direção, pode afetar de forma positiva a organização, no que tange, melhor gerenciamento e desempenho organizacional, quando comparado a presença de chefes do sexo masculino (HUANG; HUANG; LEE, 2014; LOW; ROBERTS; WHITING, 2015).

Conforme Singh e Vinnicombe (2004), atividades desempenhadas por mulheres nas salas de reuniões e atuação de funções de maior importância organizacional podem gerar um comportamento mais organizado, permitindo uma melhor gestão corporativa. Há literatura que discute a diversidade de gênero no comando de organizações, com destaque ao reflexo dessa diversidade no desempenho das organizações. Como forma de se observar o desempenho das organizações, tem-se a divulgação das demonstrações contábeis. A literatura destaca que a demora pela divulgação dessas informações contábeis pode sinalizar algum problema. $\mathrm{O}$ audit delay é uma das maneiras de se verificar o quão disposta a organização está com seus investidores (NG; TAI, 1994), já que conforme Pereira e Costa (2012), organizações com audit delay elevado, pode demonstrar que a organização tem algum problema com suas informações contábeis, inclusive diminuição de informações sobre ela referente a seu desempenho e riscos.

Nesse sentido, diante da discussão de gênero pode influenciar na gestão, sobretudo quando da composição de conselhos de administração e de comitês de auditoria, tem-se a seguinte questão que norteia essa pesquisa: Qual a relação entre o gênero na composição do conselho de administração e no comitê de auditoria com o audit delay? Para responder à questão 
de pesquisa, o objetivo desse trabalho é verificar a relação entre o gênero na composição do conselho de administração e do comitê de auditoria com o audit delay.

Como justificativa é importante ressaltar que se observa um crescimento a obrigatoriedade da presença de mulheres nos comitês e conselho de administração incentivado pelo projeto de Lei $\mathrm{n}^{\mathrm{o}} 112$ de 2010 imposta pela Senadora Maria do Carmo Alves que prevê um percentual mínimo de composição de mulheres nos conselhos de administração. Essa inserção da participação feminina pode gerar respostas rápidas e maior fortalecimento da governança corporativa nas organizações, além de reduzir o audit delay (LOW et al., 2015).

$\mathrm{Na}$ literatura norte-americana, a questão de gênero é mais discutida na pesquisa, principalmente para examinar a relação entre diversidade de gênero na diretoria e desempenho organizacional (LOW; ROBERTS; WHITING, 2015). Thiruvadi e Huang (2011) alegam que a participação de mulheres no comitê de auditoria afeta diretamente na qualidade da auditoria, e que essa qualidade é refletida em maior confiabilidade dos usuários externos das informações contábeis.

A ligação criada por esse estudo entre a diversidade de gênero e audit delay busca verificar se o gênero participante dos conselhos de administração e comitê de auditoria influência no tempo entre a data das demonstrações contábeis e a divulgação do relatório de auditoria. Os resultados podem contribuir para as organizações no momento em que pretendem compor os respectivos conselhos de administração e comitê de auditoria, na perspectiva de que a escolha dos membros destes órgãos reflete na eficácia dos mesmos.

Em relação a estruturação do estudo, foi realizada uma classificação em cinco seções além desta introdução. A seção dois refere-se à revisão de literatura, a seção três trata dos procedimentos metodológicos utilizados na pesquisa. Os resultados obtidos são expostos na quarta seção, a seção cinco apresenta as considerações finais acerca do estudo e, por fim, as referências bibliográficas.

\section{Revisão de Literatura}

\subsection{Conselho de Administração e Comitê de Auditoria}

O Conselho de Administração tem dentre suas funções, a de fiscalizar a atuação do diretor da empresa, para que minimize os conflitos com os acionistas, representando assim estes interesses (BANGE; MAZZEO, 2004). Empresas que emitem ações são obrigadas a constituir o conselho de administração pela Lei $n^{\circ}$ 6.404/1976 e apresentar neste conselho um mínimo de conselheiros, cujo tamanho varia conforme o perfil de cada empresa, mas que pode variar de 5 a 11 membros (IBGC, 2010).

O estudo de Beasley (1996) demonstra que o tamanho do conselho de administração tem relação positiva com a qualidade das demonstrações financeiras das empresas. Porém, algumas divergências são apresentadas em relação ao tamanho do conselho de administração na literatura. Aspectos positivos são relacionados a contribuição nas discussões e tomadas de decisões com mais qualidade, juntamente com conhecimento e habilidades especializadas (DALTON; DAILY, 2000). Por outro lado, uma quantidade elevada de membros em um conselho de administração pode prejudicar o debate entre os membros, havendo dificuldade de identificação sobre os membros potenciais e suas contribuições (LEVRAU; BERGHE, 2007).

Outra questão relacionada ao conselho de administração é sua diversidade, que segundo Kang, Cheng e Gray (2007) pode ser observada por duas categorias: diversidades observáveis como etnia, gênero, nacionalidade e idade e as diversidades com menor visibilidade como: a formação, experiência profissional e associações organizacionais. Os estudos de Adams e Ferreira (2009), Lehn, Patro e Zhao (2009), Gazley, Chang e Bingham (2010) buscaram avaliar 
a atuação das minorias na composição do conselho de administração, no entanto. Os estudos evidenciaram que o gênero não apresenta significância estatística, porém é uma variável predita dos resultados encontrados.

Rost e Osterloh (2009) demonstraram que a diversidade de gênero nas reuniões do conselho de administração pode trazer benefícios, como maior experiência e formação ao grupo, resultando em uma diversificação de visões nas tomadas de decisões ou resoluções de problemas, que podem não ocorrer eventualmente em um conselho de administração homogêneo, ocasionando o pensamento de grupo. A diversificação possibilita uma gestão mais eficiente, tornando o conselho mais independente, porém, pode trazer maiores conflitos ao grupo e decisões mais complexas (ÁLVAREZ; SÁNCHEZ; DOMINGUEZ, 2010).

Grosvold (2011) retrata que as discussões em torno da inclusão do gênero feminino no Conselho de Administração têm apresentado um aumento. No entanto, a participação da mulher no conselho é observada em todo o mundo como minoritária. Esta diversidade de gênero tem sido uma das formas encontradas de melhorar o conselho de administração, pois este, verifica a ação do gestor e com essa diversificação as maneiras de fiscalização sob diferentes visões, resultam em um conselho mais questionador e desafiador (YI, 2011). Para Singh e Vinnicombe (2004) a presença das mulheres no conselho de administração pode proporcionar atividades com mais atenção e melhor governança corporativa.

Low, Roberts e Whiting (2015) evidenciaram em seu estudo realizado em países asiáticos, que a presença do gênero feminino tem tido uma ascensão nos conselhos de administração e que esta presença tem um efeito positivo sobre o desenvolvimento da empresa. Fauzi e Locke (2012) investigaram a estrutura administrativa e o efeito das estruturas de propriedades em relação ao desempenho das empresas da Nova Zelândia. O resultado apresenta que o conselho de administração, propriedade dos diretores e a existência dos demais comitês, são significativamente positivos sobre o desempenho da empresa, entretanto, quando o diretor não é um executivo, acionista maioritário e diretor do sexo feminino apresentam um desempenho mais baixo em relação às variáveis anteriores.

De acordo com Pereira e Costa (2012), o conselho de administração pode adotar uma postura de troca de serviços de auditoria quando ocorre elevação do audit delay, isso porque os investidores tendem a vender suas ações ou mesmo exigir uma remuneração maior.

Oliveira (2013) salienta que outro fator que pode alterar o audit delay, é o gênero no comitê, pois a presença de mulher no Conselho de Administração pode representar uma alteração no desempenho econômico-financeiro das organizações que as possuem, porém em seu estudo, esse fator não ficou evidenciado, sendo sugeridos pelo autor novos estudos.

Low et al (2015) enfatizam que estudos sugerem que a presença de mulheres na direção proporciona maior fortalecimento de governança corporativa, respostas rápidas, aumentando assim o desempenho organizacional das corporações. Esses fatores podem melhorar a organização da empresa e então reduzir o audit delay.

Com base na discussão sobre os benefícios da mulher no Conselho de Administração, tem-se a seguinte hipótese:

H1: Há uma associação negativa e significativa da presença de mulheres no conselho de administração com o audit delay.

As leis norte-americanas determinam que todas as empresas de capital aberto listadas nas bolsas de valores dos Estados Unidos da América instituam um Comitê de Auditoria responsável pela indicação, remuneração e supervisão da Auditoria Externa e também pela solução de impasses entre a administração e a auditoria independente (SILVA et al., 2009).

No caso do Brasil, a Securities and Exchange Comissiono (SEC) forneceu a escolha para as empresas formarem o Comitê de Auditoria ou utilizarem o Conselho Fiscal adaptado às funções do Comitê de Auditoria. Porém, as opiniões sobre a implantação do Comitê de 
Auditoria ou a transformação do Conselho Fiscal adaptando-o às funções daquele Comitê podem ser bastante divergentes (FURUTA; SANTOS, 2010).

Segundo Ito, Niyama e Mendes (2008), é importante fazer a avaliação, efetividade das auditorias independentes e internas, principalmente no quesito cumprimento das obrigações estipuladas na legislação aplicada às instituições, juntamente com os regulamentos e códigos internos que fazem parte das atribuições do Comitê de Auditoria. Sharma, Naiker e Lee (2009) afirmam que os comitês de auditoria preenchem um papel importante no acompanhamento e supervisão das informações financeiras, auditoria externa e também controles internos.

Entretanto, Furuta (2010) aborda que apesar da transparência proporcionada pelo Comitê de Auditoria, ainda existe questionamentos sobre sua efetividade e contribuição para a governança corporativa, já que em alguns casos em que haviam membros qualificados, foram identificados casos de irregularidades organizacionais. No entanto, as normas impostas ao comitê de auditoria, juntamente com as características dos seus componentes, trazem maior qualidade das demonstrações contábeis e também maior segurança aos acionistas e investidores, referente a instituição.

Conforme o IBGC (2009b), o comitê de auditoria é formado por membros do conselho de administração, que têm como deveres e responsabilidades: supervisionar a gestão dos processos internos e assegurar a integridade e efetividade na produção de relatórios financeiros pelos controles internos. Dentre os deveres e responsabilidades, algumas características destacadas na literatura devem ser atendidas para que se possa ter um comitê de maneira mais fidedigna e imparcial, destacando o tamanho, independência e a expertise. (BRC, 1999; ABBOTT; PARK; PARKER, 2000; DEZOORT et al., 2002; KLEIN, 2002; YANG; KRISHNAN, 2005; DEFOND; HANN; HU, 2005; CARCELLO; HOLLINGSWORTH; NEAL, 2006; BRONSON et al. 2009; IBGC, 2009b; KENT; ROUTLEDGEA; STEWAR, 2010; VLAMINCK; SARENS, 2012). Destaca-se que este comitê seja representado por indivíduos possuidores da expertise necessária para sua função, além de independência (IBGC, 2016b).

Thiruvadi e Huang (2011) afirmam que a presença de uma mulher no comitê de auditoria pode afetar a qualidade da auditoria e as decisões da gestão de forma positiva, além de aumentar a confiança do público, já que o gênero feminino é mais preocupado com as questões ligadas aos riscos e comportamentos éticos. Thiruvadi (2012) examinou a associação entre o gênero e o comitê de auditoria, constatando que existem evidências consistentes que comitês de auditoria, com pelo menos uma mulher presente, eram capazes de satisfazer maiores contribuições de melhores práticas de governança corporativa e confiança externa, além de um papel importante para regulação das normas e decisões políticas.

Com o objetivo de investigar as associações entre honorários de auditoria e o gênero do Chief Executive Officer (CEO), Huang, Huang e Lee (2014) constataram em uma amostra de 8.402 observações em empresas norte-americanas no período de 2003 a 2010, que empresas com CEOs do gênero feminino estão relacionados com os honorários mais altos de auditoria.

Montenegro e Brás (2015) verificaram se a qualidade da auditoria muda conforme a composição do gênero dos auditores de empresas de auditoria portuguesas e as empresas auditadas por elas, sendo realizado no período de 2003 a 2006. Por meio de regressão de dados em painel, encontraram que a diversidade de gênero não tem nenhuma relação com a qualidade da informação. Porém, empresas de auditoria com uma estrutura dominadas pelo gênero feminino são relacionadas com uma maior qualidade da auditoria.

No estudo de Sultana (2015) realizado em empresas australianas entre os anos de 2004 a 2008, buscou-se verificar as caraterísticas do comitê de auditoria em relação ao audit delay. Ele evidenciou que o menor prazo foi de 35 dias e o maior prazo de 204 dias, 13\% da amostra dos membros encontrados foram do gênero feminino. No entanto, em separado, constatou-se 
que há no máximo duas mulheres presentes por comitê e as empresas Big 4 estão relacionadas em total de $57 \%$ empresas analisadas no estudo. No entanto, verificou-se que o gênero no comitê tem influência negativa sobre o audit delay, porém, não foi significante, ou seja, predita de um audit delay menor.

Em resumo, esses estudos demonstram que o gênero pode influenciar no comitê de auditoria. Com base nessas evidências elabora-se a seguinte hipótese:

H2: Há uma associação negativa e significativa da presença de mulheres no comitê de auditoria com o audit delay.

\subsection{Gênero e o Atraso do relatório de Auditoria - Audit Delay}

De acordo com a literatura internacional e nacional analisada, o assunto relacionando a diversidade de gênero presente em conselhos de administração e comitês de auditoria é bastante diversificado, principalmente no que tange ao desempenho organizacional.

A diversidade de gênero é vista como um aspecto positivo para Adams e Ferreira (2008), afirmando que a presença do gênero feminino possibilita maior desempenho, pois essa diversidade faz com que haja mais frequência de reuniões sobre aspectos organizacionais e monitoração rígida quanto às decisões.

No caso de empresas australianas, Kang, Cheng e Gray (2007) encontraram evidências comprovando que a diversidade de gênero proporciona maior independência aos conselhos, e que a presença do gênero feminino através de quotas e partidos políticos, proporciona o crescimento da atuação de mulheres executivas. Assim, a relação positiva encontrada por Carter, Simkins e Simpson (2003) sob a presença do gênero feminino no valor organizacional das empresas, reafirma que estudos nessa temática tendem a gerar boas discussões sobre o papel dessa diversidade.

O audit delay é o período da data final das demonstrações contábeis e a data de entrega do parecer da auditoria independente (NG; TAI, 1994). Em razão disso, se o audit delay for alto pode fazer com que os usuários tenham uma percepção errônea sobre o desempenho organizacional (PEREIRA, 2011). Isso pode significar que um elevado audit delay indique um risco de a empresa apresentar problemas nas demonstrações contábeis (CUNHA et al., 2013). Kalleberg e Leicht, (1991) verificaram que o desempenho da organização pode ser influenciado de alguma maneira pelo gênero, constatando que alguns resultados comprovam uma melhora de desempenho, nas organizações gerenciadas por mulheres.

Conforme NG e Tai (1994), a emissão dos relatórios financeiros das empresas tem sido uma questão de suma importância da atualidade para anúncio dos resultados, além da motivação de estudos sobre atraso do relatório de auditoria em diferentes países. NG e Tai (1994) examinaram os fatores determinantes do audit delay, a partir de uma amostra de 292 companhias listadas nos anos de 1990 e 1991. O resultado do estudo indicou que duas variáveis incluídas no modelo são significativas entre os dois anos examinados: tamanho da empresa e grau de diversificação. Já as variáveis elaboração de relatórios de itens extraordinários e data final do exercício afetaram significativamente o atraso de auditoria, demonstrando que a eficiência do auditor e da interação entre a gestão empresarial e o auditor interferem no atraso do relatório de auditoria.

Johnson, Davies e Freeman (2001) demonstram uma preocupação em relação ao audit delay já que o atraso do relatório pode implicar principalmente na qualidade da auditoria, como também no valor dos honorários pagos. Dessa maneira, os autores investigaram a influência do ano fiscal nos honorários de auditoria e atraso do relatório. Os resultados mostraram que, as organizações analisadas foram prejudicadas em termos de honorários de auditoria e atraso do 
relatório. Os autores afirmaram ainda que os honorários de auditoria podem influenciar o atraso de auditoria.

Da mesma maneira, Soltani (2002) realizou um estudo com vistas às questões de pontualidade dos relatórios financeiros organizacionais, das quais afirma que tem recebido muita atenção por parte dos órgãos reguladores e profissionais na França. $\mathrm{O}$ autor descreve que a crescente presença de investidores internacionais, contribui para a importância desta questão. Para realização da pesquisa foram verificados 5.000 relatórios anuais das companhias francesas abertas durante os anos de 1986 a 1995. Foi diagnosticado que durante o período de análise, houve uma melhora na pontualidade dos relatórios corporativos e de auditoria. Houveram também evidências de que os pareceres de auditoria modificados foram liberados mais tarde do que opiniões sem ressalvas e que, em geral, quanto mais grave a qualificação do relatório, maior é o atraso.

Já Al-Jami (2008) buscou em sua pesquisa estudar os determinantes do audit delay nos relatórios de 231 empresas de empresas financeiras e não-financeiras listadas na Bolsa de Valores de Bahrain durante o período de 1999 a 2006. Buscou identificar a relação entre os auditores e as características dos auditados, a respeito da pontualidade da divulgação dos relatórios anuais e o audit delay. Os autores constataram que os determinantes para a divulgação dos relatórios anuais sem atraso foram: o tamanho da empresa, rentabilidade e alavancagem. Nenhuma evidência foi encontrada para suportar o efeito de uma contabilidade mais complexa e empresa de auditoria (Big Four ou não-Big Four). Além disso, as variáveis de governança corporativa foram significativas para um menor audit delay.

Krishnan e Yang (2009) focalizaram seus estudos no audit delay devido à importância atribuída a qualidade das informações, visto que o atraso do relatório de auditoria implica na perda de qualidade do relatório em si. Dessa forma, os autores buscaram investigar de que maneira o audit delay impacta na qualidade dessas informações contábeis, principalmente no que tange às novas regras contábeis exigidas após a Lei Sarbanes-Oxley, podendo ser evidenciado nesse estudo que após a cobrança das novas normas, o prazo da emissão dos relatórios diminuiu, sendo este fenômeno explicado pelo atendimento das organizações às novas ordens. Porém de acordo com os autores, essa aceleração pode ter prejudicado a qualidade das informações divulgadas, visto que o prazo ampliado provoca uma pressão, reduzindo assim a qualidade da auditoria.

Em relação a diversidade de gêneros em CEOs, sob a ótica de mercado e desempenho (crescimento e rentabilidade), Davis et al. (2010) encontraram vestígios de que organizações que detinham chefes mulheres obtiveram desempenho de mercado e desempenho financeiro superiores, constatando que a liderança de mulheres pode superar a dos CEOs homens.

Já nos estudos nacionais sobre o atraso do relatório, Pereira e Costa (2012) pesquisaram sobre os determinantes do audit delay de empresas brasileiras listadas na Bolsa de Valores de São Paulo entre o período de 1999 a 2008. Os resultados apontaram que a emissão de opinião com ressalva, a divulgação de prejuízos e o início do processo de migração do modelo contábil brasileiro ao internacional estão relacionados com o atraso na emissão dos pareceres dos auditores, porém, quanto maior forem os clientes da auditoria, as opiniões tendem a ser mais rápidas.

Com o objetivo de verificar a relação entre as características do comitê de auditoria e o audit delay nas empresas listadas na BM\&FBovespa, Cunha et al. (2015) concluíram que quando o comitê de auditoria e outros membros independentes possuem expertise nas áreas de administração e contabilidade, o prazo do relatório do auditor independente é menor. Quanto às características da empresa auditada e da firma de auditoria não foi encontrada uma relação significante com o audit delay. 


\title{
2.3 Características do setor IBrX 100
}

O IBrX 100 é um indicador de desempenho médio das cotações dos 100 ativos de maior negociabilidade e representatividade do mercado de ações brasileiro e sua divulgação foi iniciada no ano de 1997. Todas as empresas pertencentes a esse grupo estão exclusivamente listadas na BM\&FBovespa e atendem aos critérios específicos da bolsa de valores. Não estão incluídos nesse universo as Brazilian Depositary Receipts (BDRs) e ativos de companhias em recuperação judicial ou extrajudicial, regime especial de administração temporária, intervenção ou que sejam negociados em qualquer outra situação especial de listagem (BM\&FBOVESPA, 2015).

O IBrX 100 é um índice de retorno total, ou seja, "é um indicador que procura refletir não apenas as variações nos preços dos ativos integrantes do índice no tempo, mas também o impacto que a distribuição de proventos por parte das companhias emissoras desses ativos teria no retorno do índice" (BM\&FBOVESPA, 2014, p. 2).

Para que uma empresa seja enquadrada no índice IBrX 100, são considerados:

\begin{abstract}
“[...] na carteira do índice, os valores referentes a: dividendos; juros sobre capital próprio e rendimentos (pelo valor líquido de imposto); direitos de subscrição (preço com direito descontado do preço ex-teórico); valor de qualquer ativo recebido que seja diferente dos ativos originalmente possuídos; valor de quaisquer direitos de subscrição de ativos diferentes dos ativos originalmente possuídos.

- São mantidos na carteira do índice os ativos recebidos a título de bonificação ou desdobramento.

- São incorporados na carteira os ativos, na mesma espécie e classe, decorrentes de subscrições consideradas economicamente vantajosas para os investidores.

- Após o encerramento do último pregão "com-direito", o provento, em dinheiro, é incorporado em todos os demais ativos integrantes da carteira, na proporção de suas respectivas participações.

O valor total da carteira é recalculado utilizando-se o preço "exteórico" do ativo que distribuiu o provento e o redutor é alterado de forma que o valor do índice mantenhase constante. No caso de algum provento em ações aprovado ser homologado parcialmente, ou não ser homologado, a quantidade de ações integrantes da carteira será reduzida proporcionalmente, de forma a refletir a real quantidade de ações disponíveis para negociação. Esse ajuste será efetuado no pregão subsequente ao recebimento, pela BM\&FBOVESPA, da comunicação expedida pela empresa emissora informando esses fatos. O redutor do índice será adequado, de forma que o valor do índice não sofra alteração" (BM\&FBOVESPA, 2014, p. 2 e 3 ).
\end{abstract}

Para o cálculo no índice, a BM\&FBovespa calcula o IBrX de forma atualizada sempre se baseando nos últimos preços negociados no mercado à vista. Assim, para se manter enquadrada neste índice, a empresa precisa possuir os melhores valores contados nos últimos 12 meses, além de terem sido negociadas em pelo menos $70 \%$ dos pregões ocorridos nos 12 meses anteriores à formação da carteira.

Todos os índices são criados pela BM\&FBovespa dos quais, realiza a compilação, cálculo e publicação dos índices através de critérios e métodos criados para avaliar a qualidade das informações. Para a avaliação dos índices, a BM\&FBovespa possui um comitê designado na realização, manutenção e aprimoramento das metodologias aplicadas para o cálculo e avaliação de todos os índices utilizados como base pela bolsa de valores nacional (BM\&FBOVESPA, 2014, p. 12).

Para o desenvolvimento da presente pesquisa, optou-se por trabalhar com as empresas listadas no índice IBrX 100, justamente por ter o entendimento de que essas 100 empresas estão classificadas como as melhores organizações em relação ao seu alto índice de negociabilidade. 
Sendo assim, percebe-se que essas empresas compõe as mais representativas e relevantes organizações do mercado acionário brasileiro, viabilizando, dessa forma, o aprofundamento e discussões relacionadas ao tema proposto.

\section{Procedimentos Metodológicos}

O presente estudo teve como objetivo verificar qual a relação entre do gênero na composição do conselho de administração e do comitê de auditoria com o audit delay. A população do estudo foi constituída pelas empresas que estão presentes no índice IBrX 100 da BM\&FBovespa. Foram excluídas 18 empresas do setor financeiro por possuir características particulares em relação aos outros setores.

A escolha das empresas do índice IBrX 100 foi direcionada, pelo fato de elas estarem classificadas entre as 100 melhores empresas de acordo com o índice de negociabilidade, apurado os 12 últimos meses, negociadas nos pregões em pelo menos $70 \%$ dentro do mesmo período. Justifica-se ainda a escolha desta amostra devido o $\mathrm{IBrX} 100$ ser um indicador de desempenho médio das cotações dos 100 ativos de maior negociabilidade e representatividade do mercado de ações brasileiro.

Além das empresas do setor financeiro, também foram excluídas 7 empresas por não conterem todas as informações necessárias para o referido estudo, resultando em uma amostra final de 75 empresas. As variáveis do estudo estão demonstradas no Quadro 1.

Quadro 1 - Variáveis da pesquisa

\begin{tabular}{|c|c|c|c|}
\hline Variável & Sub-variáveis & Mensuração & Autores \\
\hline \multicolumn{4}{|c|}{ Dependente } \\
\hline Audit Delay & & $\begin{array}{l}\text { Número de dias entre o } \\
\text { encerramento de exercício e a } \\
\text { data do parecer de auditoria } \\
\text { independente. }\end{array}$ & $\begin{array}{l}\text { Hossain, Taylor (1998); Al- } \\
\text { Ajmi (2008); Afify (2009); } \\
\text { Pereira, Costa (2012). }\end{array}$ \\
\hline \multicolumn{4}{|c|}{ Independente } \\
\hline \multirow{3}{*}{$\begin{array}{l}\text { Características do } \\
\text { comitê de auditoria }\end{array}$} & Tamanho & $\begin{array}{l}\text { Quantidade de membros que } \\
\text { compõem o comitê de auditoria. }\end{array}$ & $\begin{array}{c}\text { Xie, Davidson, Dadalt } \\
\text { (2003); Yang, Krishnan } \\
\text { (2005); PWC (2007); IBGC } \\
\text { (2009b); Kent et al. (2010); } \\
\text { Comissão de Valores } \\
\text { Mobiliários [CVM] (2011) }\end{array}$ \\
\hline & Independência & $\begin{array}{lcc}\text { Quantidade } & \text { de } & \text { membros } \\
\text { independentes } & \text { no } \\
\text { auditoria. } & & \\
\text { autê de }\end{array}$ & $\begin{array}{l}\text { IBGC (2009b); Klein } \\
(2002) ; \text { CVM (2011) }\end{array}$ \\
\hline & Expertise & 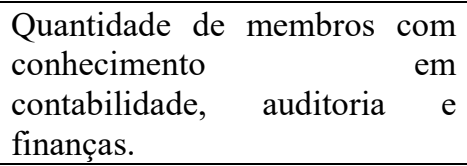 & $\begin{array}{l}\text { Zhang, Zhou e Zhou (2007); } \\
\text { IBGC (2009b); CVM, } \\
\text { (2011); Deloitte (2013) }\end{array}$ \\
\hline \multirow[b]{2}{*}{ Gênero } & $\begin{array}{l}\text { Mulher no conselho } \\
\text { de administração }\end{array}$ & $\begin{array}{l}\text { Se há existência de mulher no } \\
\text { conselho de adm. }=1 \text {, senão }=0 \text {. }\end{array}$ & $\begin{array}{l}\text { Adams e Ferreira (2009); Yi } \\
\text { (2011) }\end{array}$ \\
\hline & $\begin{array}{l}\text { Mulher no comitê de } \\
\text { auditoria }\end{array}$ & $\begin{array}{l}\text { Se há existência de mulher no } \\
\text { comitê de auditoria }=1 \text {, senão }= \\
0 .\end{array}$ & Sultana, N. et al. (2015) \\
\hline \multirow{2}{*}{$\begin{array}{l}\text { Características da } \\
\text { empresa auditada }\end{array}$} & $\begin{array}{c}\text { Tamanho da empresa } \\
\text { auditada }\end{array}$ & Log do total do ativo. & $\begin{array}{c}\text { Nazri, Smith e Ismail, } \\
\text { (2012); Tang, Du e Hou, } \\
\text { (2013 }\end{array}$ \\
\hline & Endividamento & Passivo Total / Ativo total & $\begin{array}{c}\text { Alkhatib e Marji (2012), Ika } \\
\text { e Ghazali (2012). }\end{array}$ \\
\hline
\end{tabular}

Continua 
Quadro 1 - Variáveis da pesquisa

\begin{tabular}{|c|l|l|c|}
\hline Variável & \multicolumn{1}{|c|}{ Sub-variáveis } & Mensuração & \multicolumn{1}{c|}{ Autores } \\
\hline $\begin{array}{c}\text { Características da } \\
\text { firma de auditoria }\end{array}$ & Tamanho da Firma & Se Big 4 =1 senão 0. & $\begin{array}{c}\text { DeAngelo (1981); Ireland } \\
\text { (2003); Leventis e } \\
\text { Caramanis (2005). }\end{array}$ \\
\cline { 2 - 4 } & Honorários & $\begin{array}{l}\text { Log do valor dos honorários de } \\
\text { auditoria. }\end{array}$ & $\begin{array}{c}\text { Hope e Langli (2010); } \\
\text { Camargo (2012); Camargo } \\
\text { et al. (2012). }\end{array}$ \\
\hline
\end{tabular}

Fonte: Adaptado de Cunha et al. (2015)

Para a coleta dos dados das variáveis citadas no Quadro 1, fez-se uso de dados provenientes do sítio da BM\&FBovespa. Foram separadas as empresas que continham a existência do comitê de auditoria.

Com os dados coletados referente a existência do comitê de auditoria, fez-se a coleta referente às características da referida variável, conferido na subseção 12.7 do Formulário de Referência, composição do conselho de administração. Também se pesquisou, neste mesmo formulário, informações referentes ao tamanho, independência e a expertise do comitê de auditoria.

Já os dados das variáveis referente às características da empresa auditada, foram extraídos do banco de dados do software Economática ${ }^{\circledR}$. Logo após, os dados foram tabulados em planilha eletrônica. A coleta foi realizada nos meses de junho e julho de 2015. Para análise dos dados, utilizou-se o software estatístico SPSS v.21, tanto para elaborar da estatística descritiva como para a análise da regressão linear.

\section{Análise dos Resultados}

Inicialmente é apresentada a análise descritiva dos dados resultante das empresas na Tabela 1.

Tabela 1 - Análise descritiva das variáveis do estudo

\begin{tabular}{|c|c|c|c|c|c|c|}
\hline & $\mathbf{N}$ & Mínimo & Máximo & Média & $\begin{array}{l}\text { Desvio } \\
\text { Padrão }\end{array}$ & Variância \\
\hline Tamanho do Comitê de Auditoria & 75 & 0,00 & 7,00 & 1,40 & 1,74 & 3,03 \\
\hline Independência do Conselho de Administração & 75 & 0,00 & 11,00 & 3,03 & 2,33 & 5,43 \\
\hline Expertise & 75 & 0,00 & 3,00 & 0,64 & 0,98 & 0,96 \\
\hline Mulher no Comitê de Auditoria & 75 & 0,00 & 1,00 & 0,08 & 0,27 & 0,08 \\
\hline Mulher no Conselho de Administração & 75 & 0,00 & 1,00 & 0,56 & 0,50 & 0,25 \\
\hline Tamanho da Empresa & 75 & 4,20 & 8,90 & 6,99 & 0,67 & 0,45 \\
\hline Endividamento & 75 & 0,25 & 0,93 & 0,57 & 0,17 & 0,03 \\
\hline Firma de Auditoria Big Four & 75 & 0,00 & 1,00 & 0,92 & 0,27 & 0,08 \\
\hline Honorário da Auditoria & 75 & 4,51 & 7,37 & 6,14 & 0,52 & 0,27 \\
\hline Audit Delay & 75 & 26,00 & 112,00 & 62,35 & 17,77 & 315,91 \\
\hline
\end{tabular}

Fonte: Dados da pesquisa.

Pode-se verificar na Tabela 1, que houve empresas nas quais não se constatou a existência do comitê de auditoria. No entanto, houve 31 empresas que o possuíam comitê de auditoria e o número de integrantes máximos foi de 7 integrantes, sendo que, a média sobre todas as empresas da amostra resultou em 1,4 integrante. No que tange às 31 empresas que possuem comitê de auditoria, a média apresentou 3,18 integrantes.

Em relação a expertise, ou conhecimento dos integrantes do comitê de auditoria, observa-se na Tabela 1 que $37 \%$ das empresas analisadas continham pelo menos um membro 
com expertise, já outras organizações apresentaram até 3 membros com essas caraterísticas. No entanto, no conselho de administração, constatou-se que há empresas com nenhum membro independente como mínimo e empresas com 11 conselheiros independentes, tendo uma média da amostra em torno de 3 membros.

A mulher se faz presente em 42 conselhos de administração da amostra, ou seja, pelo menos um integrante é mulher, em linha do que abordam Low, Roberts e Whiting (2015), de que a presença de mulheres tem tido uma ascensão nos conselhos de administração e que esta presença tem um efeito positivo sobre o desenvolvimento da empresa.

A fim de evidenciar a influência do gênero feminino no Audit Delay, faz-se importante destacar as empresas as quais apresentaram em sua composição do conselho de administração a presença de pelo menos uma mulher na sua composição, estas são apresentadas na Tabela 2.

Tabela 2 - Relação de empresas que apresentaram presença da mulher no conselho de administração

\begin{tabular}{cccc}
\hline AES TIETE & DURATEX & LOCALIZA & P.ACUCAR-CBD \\
\hline ANIMA & ELETROBRAS & LOJAS AMERIC & RAIADROGASIL \\
\hline ARTERIS & ELETROPAULO & LOJAS RENNER & RUMO LOG \\
\hline BRASKEM & EMBRAER & M.DIASBRANCO & SABESP \\
\hline CCR SA & ESTACIO PART & MAGAZ LUIZA & SOUZA CRUZ \\
\hline CEMIG & EVEN & MARCOPOLO & TAESA \\
\hline CESP & FIBRIA & MARFRIG & TELEF BRASIL \\
\hline COPASA & HYPERMARCAS & MILLS & TIM PART S/A \\
\hline CPFL ENERGIA & KLABIN S/A & MRV & TOTVS \\
\hline DIRECIONAL & KROTON & NATURA & OI \\
\hline & LIGHT S/A & &
\end{tabular}

Fonte: Dados da pesquisa.

Dentre as empresas apresentadas na Tabela 2, as empresas CCR S.A, FIBRIA, M. DIASBRANCO, MARFRIG E TOTVS são as empresas que evidenciaram a presença do gênero feminino no seu conselho de administração e no comitê de auditoria.

Para melhor evidenciação desses resultados, apresenta-se a Tabela 3, com a distribuição dos membros independentes das empresas analisadas.

Tabela 3 - Independência do Conselho de Administração

\begin{tabular}{c|c|c}
\hline Quantidade de Membros & Quantidade de Empresas & Percentual \\
\hline 0 & 13 & $17,3 \%$ \\
\hline $1 \vdash 4$ & 35 & $46,7 \%$ \\
\hline $4 \vdash 7$ & 21 & $28,0 \%$ \\
\hline $7 \vdash 11$ & 5 & $6,7 \%$ \\
\hline $11 \vdash 14$ & 1 & $1,3 \%$ \\
\hline Total & 75 & $100,0 \%$ \\
\hline
\end{tabular}

Fonte: Dados da pesquisa.

Conforme a Tabela 3, observa-se que aproximadamente $47 \%$ da amostra contém de 1 a 3 integrantes no conselho de administração do tipo independente, assim, não tendo uma função efetiva na empresa. Também se verifica que $28 \%$ das empresas analisadas compõem o conselho de administração com 4 a 6 integrantes independentes, resultando em um conselho mais independente que os demais, sinalizando aos acionistas e demais stakeholders uma possibilidade de informações mais seguras.

A presença da mulher no conselho de administração é maior que no comitê de auditoria. Observou-se que o percentual da presença de mulher no conselho de administração é de 
aproximadamente $56 \%$, enquanto no comitê de auditoria é de apenas $8 \%$ nas empresas que possuem comitê.

Verifica-se que as firmas de auditoria chamadas de Big-4, prestam seus serviços em quase todas as empresas da amostra, encontrando-se presentes em torno de $92 \%$ das empresas da amostra do estudo.

Em relação ao audit delay, as empresas presentes à amostra desta pesquisa, têm em média 62 dias entre a data das demonstrações contábeis e a data do relatório de auditoria. Houve organizações que apresentaram um prazo menor para essa publicação, chegando a 26 dias, porém, encontrou-se empresas com até 112 dias de delay. Esses dados são apresentados na Tabela 4.

Tabela 4 - Audit Delay das empresas

\begin{tabular}{c|c|c}
\hline Audit Delay & Quantidade & Percentual \\
\hline $1 \vdash 26$ & 0 & $0,00 \%$ \\
\hline $26 \vdash 51$ & 20 & $26,67 \%$ \\
\hline $51 \vdash 76$ & 35 & $46,67 \%$ \\
\hline $76 \vdash 101$ & 18 & $24,00 \%$ \\
\hline $101 \vdash 126$ & 2 & $2,67 \%$ \\
\hline Total & 75 & $100,00 \%$ \\
\hline
\end{tabular}

Fonte: Dados da pesquisa.

Conforme a Tabela 4, percebe-se que nenhuma empresa da amostra do estudo teve um delay no relatório de auditoria inferior a 25 dias. No período de 51 a 75 dias de delay, o mesmo representou em torno de 46,67\% dos casos. Em seu estudo, Sultana (2015) constatou que o período de divulgação do relatório de auditoria foi de 35 a 204 dias, com uma média de 80,67 dias. Já o estudo de Al-Jasim (2008) evidenciou que a média de dias para divulgação foi de 48 dias.

A partir do resultado apresentado na Tabela 4 e estudos anteriores, percebe-se que, para as empresas brasileiras a média de audit delay foi de 62,35 dias, ou seja, uma média inferior em relação ao estudo de Sultana (2015) e maior que Al-Jasim (2008). Observou-se que para 26 a 50 dias de Audit Delay, a presença da mulher no conselho de administração foi de $50 \%$ das empresas e no comitê de auditoria de $15 \%$ das empresas. Porém, para Audit Delay de 51 a 75 dias, a concentração foi de $40 \%$ para o conselho de administração e de $8 \%$. Já para 76 a 100 dias de Audit Delay apenas a presença da mulher no conselho de administração com $38 \%$ foi evidenciada. Desta forma, sinaliza-se que a presença da mulher tende a ter uma relação negativa com o Audit Delay.

Após a análise descritiva dos dados, utilizou-se da análise da regressão linear para analisar as variáveis que possam descrever melhor a variável dependente. Destaca-se que antes da análise da regressão, buscou-se analisar a intensidade e o sentido das relações entre as variáveis, a partir do cálculo do coeficiente de correlação de Pearson. Aplicou-se também, o teste não paramétrico de Kolmogorov-Smirnov para verificar a normalidade dos dados, que evidenciou uma distribuição normal das variáveis a um nível de 5\% ( $p$-value $<0,05)$. Os resultados encontram-se na Tabela 5.

Na Tabela 5, com resultados da regressão linear, verifica-se significância no modelo utilizado com um poder explicativo próximo de $25 \%$. Com isso a hipótese nula de que não há relação das variáveis analisadas não é aceita, pois há variáveis como independência do conselho de administração, a presença da mulher no comitê de auditoria e o tamanho da empresa são significantes no modelo. 
Referente à análise da regressão, verifica-se que existem duas variáveis explicativas para o audit delay a nível de 5\%, que são a presença da mulher no comitê de auditoria e tamanho da empresa.

Tabela 5 - Regressão das variáveis em função do Audit Delay

\begin{tabular}{|c|c|c|c|c|c|}
\hline \multirow[t]{2}{*}{ Modelo } & \multicolumn{2}{|c|}{$\begin{array}{l}\text { Coeficientes não } \\
\text { padronizados }\end{array}$} & \multirow{2}{*}{$\begin{array}{c}\begin{array}{c}\text { Coeficientes } \\
\text { padronizados }\end{array} \\
\text { Beta } \\
\end{array}$} & \multirow[t]{2}{*}{$\mathbf{T}$} & \multirow[t]{2}{*}{ Sig. } \\
\hline & B & Modelo padrão & & & \\
\hline (Constante) & 38,281 & 29,949 & & 1,278 & 0,206 \\
\hline Tamanho do Comitê de Auditoria & 0,035 & 1,941 & 0,003 & 0,018 & 0,986 \\
\hline $\begin{array}{l}\text { Independência do Conselho de } \\
\text { Administração }\end{array}$ & $-0,673$ & 0,919 & $-0,088$ & $-0,732$ & $0,067 * *$ \\
\hline Expertise & $-1,014$ & 3,151 & $-0,056$ & $-0,322$ & 0,749 \\
\hline Mulher no Comitê de Auditoria & $-33,158$ & 15,479 & $-0,510$ & $-2,142$ & $0,036^{*}$ \\
\hline Mulher no Conselho Administração & $-2,672$ & 6,679 & $-0,075$ & $-0,400$ & 0,690 \\
\hline Tamanho da Empresa & 6,747 & 3,220 & 0,254 & 2,095 & $0,040 *$ \\
\hline Endividamento & $-18,520$ & 11,701 & $-0,182$ & $-1,583$ & 0,118 \\
\hline Firma de auditoria Big Four & 10,401 & 7,256 & 0,160 & 1,433 & 0,157 \\
\hline Honorário da Auditoria & $-2,313$ & 4,081 & $-0,067$ & $-0,567$ & 0,573 \\
\hline $\mathrm{R}$ & \multicolumn{5}{|c|}{0,497} \\
\hline $\mathrm{R}^{2}$ & \multicolumn{5}{|c|}{0,247} \\
\hline $\operatorname{Sig}(\mathrm{F})$ & \multicolumn{5}{|c|}{$0,039 *$} \\
\hline
\end{tabular}

Legenda: *Sig. a 5\%; ** Sig. a 10\%.

Fonte: Dados da pesquisa.

A presença da mulher no comitê de auditoria que é uma das variáveis principais do estudo, obteve um valor no seu coeficientes de $-33,158$, tendo como significado que a presença do gênero feminino dentro do comitê de auditoria tende a quase eliminar o Audit Delay quando comparado somente com a constante, evidenciando que a presença de gênero feminino influencia no número de dias para a divulgação do relatório de auditoria (audit delay) das empresas listadas no índice do IBrX 100, convergente ao estudo de Sultana (2015), que verificou se o gênero no comitê tem uma influência negativa sobre o audit delay, no entanto, $\mathrm{o}$ estudo não apresentou significância.

O resultado converge também para o encontrado por Thiruvadi (2012), de que existem evidências consistentes de que comitê de auditoria, com presença de pelo menos uma mulher, contribui para melhores práticas de governança corporativa e confiança externa, além de um papel importante para regulação das normas e decisões políticas.

Com este achado, verifica-se que a presença do gênero feminino no comitê de auditoria apresentou uma associação negativa com o audit delay, o que faz aceitar a hipótese 2 de que há uma associação negativa significativa da presença de mulheres no comitê de auditoria e o audit delay.

Em relação a hipótese 1 de que há uma associação negativa e significativa da presença de mulheres no conselho de administração com o audit delay, não se aceita a hipótese, pois a variável presença do gênero feminino não foi significante para as empresas listadas no $\mathrm{IBrX}$ 100. Desta forma, o estudo confirma o que Adams e Ferreira (2009), Lehn, Patro e Zhao (2009), Gazley, Chang e Bingham (2010) já destacaram, de que o gênero no conselho de administração não apresenta significância estatística, porém sendo uma variável predita dos resultados encontrados. Há ainda, uma ligação com os resultados de Oliveira (2013), de que o fator que pode alterar o audit delay é a presença do gênero no comitê de auditoria, e que a presença de mulher no Conselho de Administração não ficou evidenciado, da mesma forma que no presente estudo. 
As variáveis tidas como de controle: Tamanho do Comitê de Auditoria, Independência do Conselho de Administração, Expertise, Tamanho da Empresa, Endividamento, Firma de auditoria Big Four e o Honorário da Auditoria, apenas duas variáveis mostraram-se significantes no modelo para empresas presente no $\operatorname{IBrX} 100$, sendo eles o tamanho da empresa e a independência do conselho de administração.

A variável explicativa tamanho da empresa no modelo, apresentou-se com uma relação positiva entre o tamanho da organização e o audit delay, constatando-se que quanto maior a empresa, maior também será o número de dias no atraso da divulgação do relatório de auditoria. Essa constatação pode dar indícios de que empresas de maior porte são mais complexas, necessitando de uma gama maior de testes no processo de auditoria e assim absorver maior tempo para as tarefas. Esta constatação é contrária aos estudos de NG e Tai (1994) e Al-Jasim (2008), nos quais se obteve o resultado inversamente proporcional, ou seja, quanto maior a empresa, menor seria o seu audit delay, sendo explicado pelos autores que estas empresas de porte maior, provavelmente passaram por auditorias mais cedo do que outras empresas.

A nível de $10 \%$, o modelo apresentou a variável explicativa de independência do conselho de administração, no qual permite afirmar que quanto mais independente o conselho de administração das empresas analisadas na amostra do estudo, menor tende a ser o número de dias no atraso da divulgação do relatório de auditoria, demonstrando que organizações que detém um maior número de membros independentes presentes no conselho, demonstram maior confiança e segurança aos investidores e auditores a respeito das ações tomadas como medidas decisórias da organização. Isso porque esses membros são menos suscetíveis a envolvimentos de ações oportunas, já que não estão inseridos de forma efetiva na empresa.

Em relação às demais variáveis, pôde-se observar que a expertise, endividamento e os honorários representam coeficientes negativos. Como estas variáveis não apresentaram significância no modelo, não se pode inferir que influenciam no audit delay. Já as variáveis explicativas tamanho do comitê de auditoria, e se é auditado por firma Big-4, presentes no modelo deste estudo, apresentaram coeficientes positivos. Com isso, o estudo demonstra que quando há mulheres tanto no conselho de administração quanto no comitê de auditoria, há uma diminuição no audit delay da empresa.

\section{Conclusões}

Esse estudo teve por objetivo verificar a relação entre o gênero na composição do conselho de administração e do comitê de auditoria com o audit delay. Para tanto, realizou-se uma pesquisa descritiva, por meio de pesquisa documental, com abordagem quantitativa. A amostra compreendeu as companhias listadas no IBRX 100.

Para alcançar o objetivo do artigo estabeleceu-se duas hipóteses para teste. A hipótese 1, de que "há uma associação negativa e significativa da presença de mulheres no conselho de administração com o audit delay" não foi aceita. O resultado encontrado não apresentou significância, demonstrando que a presença de mulheres no conselho de administração não apresentou associação com o audit delay. Este resultado alinha-se ao achados de Adams e Ferreira (2009), Lehn, Patro e Zhao (2009), Gazley, Chang e Bingham (2010) e Oliveira (2013).

A hipótese 2 de que "há uma associação negativa e significativa da presença de mulheres no comitê de auditoria com o audit delay", evidenciou-se significativa, ou seja, esta hipótese é aceita no presente estudo. Foi possível evidenciar que a presença de gênero feminino influencia no número de dias para a divulgação do relatório de auditoria (audit delay) das empresas listadas no índice do IBrX 100. O resultado alinha-se ao estudo de Thiruvadi (2012), no qual encontrou evidências consistentes de que comitês de auditoria com pelo menos uma mulher era 
capaz de apresentar melhores práticas de governança corporativa e confiança externa, além de um papel importante para regulação das normas e decisões políticas.

Ademais, observa-se que a presença do gênero feminino no comitê de auditoria é menor que no conselho de administração. Nenhuma empresa obteve atraso no relatório de auditoria menor de 26 dias, com uma média de audit delay em torno de 51 a 75 dias. Comparativamente ao estudo de Al-Jasim (2008), constatou-se que empresas brasileiras têm um período menor de divulgação dos relatórios de auditoria.

Em relação a expertise dos membros do conselho de auditoria, observou-se que há poucos integrantes nas empresas analisadas, nas quais apenas $37 \%$ das empresas analisadas continham membro com expertise. $\mathrm{O}$ tamanho da empresa se mostrou significante com seu coeficiente positivo, o que sinaliza que as empresas maiores provêm de um maior audit delay. Ainda, para a amostra investigada, constatou-se que a independência do conselho de administração se mostrou estatisticamente e inversamente proporcional ao audit delay.

Conclui-se com este estudo, que para as empresas que compõe o IBrX 100, a presença da mulher no comitê de auditoria está associada a uma redução no prazo de divulgação do relatório do auditor (audit delay). No entanto, a presença da mulher no conselho de administração não se evidencia como fator de redução no audit delay, da mesma forma como já destacado por Adams e Ferreira (2009), Lehn, Patro e Zhao (2009), Gazley, Chang e Bingham (2010) e Oliveira (2013).

Destaca-se ainda que o tamanho da empresa e a independência do conselho de administração foram significantes no modelo final com relação ao audit delay. Também se observa que o audit delay das empresas do IBrX 100 é menor em comparação com os estudos de Hossain, Taylor (1998); Al-Ajmi (2008); Afify (2009) e Pereira, Costa (2012).

Como limitações do estudo, menciona-se o número restrito de empresas que foram analisadas, além da limitação de informações de algumas delas. Para trabalhos futuros, recomenda-se o uso dessa técnica de análise de dados em grupos ou setores de empresas para confirmar o poder da influência do gênero em cargos de gestão ou liderança organizacional. Além disso, outras variáveis e métodos estatísticos podem ser utilizados para avaliar a influência desses dados. Outra possibilidade de estudo futuro, consiste em verificar o fenômeno acerca do gênero numa perspectiva longitudinal em órgãos organizacionais que delineiam boas práticas em diferentes níveis de governança corporativa.

\section{Referências}

ADAMS, R. B.; FERREIRA, D. Women in the boardroom and their impact on governance and performance. Journal of financial economics, v. 94, n. 2, p. 291-309, 2009. https://doi.org/10.1016/j.jfineco.2008.10.007

AFIFY, H. A. E. Determinants of audit report lag: Does implementing corporate governance have any impact? Empirical evidence from Egypt. Journal of Applied Accounting Research, v. 10, n. 1, p. 56-86, 2009.

AL-AJMI, J. Audit and reporting delays: Evidence from an emerging market. Advances in Accounting, v. 24, n. 2, p. 217-226, 2008. https://doi.org/10.1016/j.adiac.2008.08.002

ALKHATIB, K.; MARJI, Q. Audit reports timeliness: Empirical evidence from Jordan. ProcediaSocial and Behavioral Sciences, v. 62, p. 1342-1349, 2012.

https://doi.org/10.1016/j.sbspro.2012.09.229 
ALMEIDA, R. S.; KLOTZLE, M. C.; PINTO, A. C. F. Composição do conselho de Administração no setor de energia elétrica do Brasil. Revista de Administração da UnimepUnimep Business Journal, v. 11, n. 1, p. 156-180, 2013.

ÁLVAREZ, I.; SÁNCHEZ, I. M.; DOMINGUEZ, L. The influence of gender diversity on corporate performance. Revista de Contabilidad, v. 13, n. 1, p. 53-88, 2010.

BANGE, M. M.; MAZZEO, M. A. Board composition, board effectiveness, and the observed form of takeover bids. The Review of Financial Studies, v. 17, n. 4, 2004. https://doi.org/10.1093/rfs/hhh001

BEASLEY, M. S. An empirical analysis of the relation between the board of director composition and financial statement fraud. Accounting Review, p. 443-465, 1996.

http://www.jstor.org/stable/248566

BM\&FBOVESPA. Manual de Definições e Procedimentos dos Índices da BM\&FBOVESPA. São Paulo, BM\&FBOVESPA, 2014. Disponível em:

http://bvmf.bmfbovespa.com.br/indices/download/Manual-de-procedimentos-pt-br.pdf Acesso em 14 de junho de 2017.

BM\&FBOVESPA. Metodologia do índice Brasil 100. São Paulo, BM\&FBOVESPA, 2015.

Disponível em:

http://www.bmfbovespa.com.br/lumis/portal/file/fileDownload.jsp?fileId=8A828D29514A32670 1516E6C30E76F87. Acesso em 14 de junho de 2017.

BM\&FBOVESPA. Manual de Definições e Procedimentos dos Índices da BM\&FBOVESPA. Disponível em: $<$ http://www.bmfbovespa.com.br/pt_br/produtos/indices/indices-amplos/indicebrasil-100-IBrX-100.htm>. Acessado em 10 de jun. de 2017.

BRASIL. Lei $n^{\circ} 6.404$ de dezembro de 1976. Disposições sobre as sociedades por ações.

Disponível em: < http://www.planalto.gov.br/ccivil_03/leis/L6404compilada.htm>. Acessado em 03 de jun. 2015.

CAMARGO, R. V. W. Determinantes dos pareceres dos auditores independentes emitidos às companhias negociadas na BM\&FBOVESPA. 206 f. Dissertação (Mestrado) - Programa de Pós-Graduação em Contabilidade, Universidade Federal de Santa Catarina, Florianópolis. 2012

CAMARGO, R. V. W.; PEPINELLI, R. C. C.; DUTRA, M. H.; ALBERTON, L. Determinantes dos pareceres dos auditores independentes emitidos às companhias negociadas na BM\&FBovespa In: Congresso USP de Controladoria e Contabilidade, 12., 2012, São Paulo. Anais... São Paulo: FEA-USP. 2012

CARTER, D. A.; SIMKINS, Betty J.; SIMPSON, W. Gary. Corporate governance, board diversity, and firm value. Financial review, v. 38, n. 1, p. 33-53, 2003. doi:10.1111/15406288.00034

CHAN, A. M. Y.; LIU, G.; SUN, J. Independent audit committee members' board tenure and audit fees. Accounting \& Financial, v. 53, n. 4, p. 1129-1147, 2013. doi:10.1111/j.1467629X.2012.00490.x 
CRAMER, L.; BRITO, M. J.; CAPPELLE, M. C. A. As representações sociais das relações de gênero na educação superior: a inserção do feminino no universo masculino. In: Encontro da Associação Nacional de Pós-Graduação em Administração, v. 25, 2001. Anais..., 2001.

CUNHA, P. R. et al. Características do comitê de auditoria e os reflexos no gerenciamento de resultados nas empresas listadas na BM\&FBOVESPA. Revista de Contabilidade do Mestrado em Ciências Contábeis da UERJ, v. 18, n. 3, p. 02-19, 2013.

CUNHA, P. R. et al. Relação entre as Características do Comitê de Auditoria e o Atraso da Emissão do Relatório da Auditoria Independente (Audit Delay). Contabilidade, Gestão e Governança, v. 18, n. 3, 2015.

DALTON, D.; DAILY, C. The board and financial performance: bigger is better. NACD Director's Monthly, p. 1-5, 2000.

DAVIS, P. S. et al. The influence of CEO gender on market orientation and performance in service small and medium-sized service businesses. Journal of Small Business Management, v. 48, n. 4, p. 475-496, 2010. doi:10.1111/j.1540-627X.2010.00305.x

DEANGELO, L. E. Auditor independence, 'low balling', and disclosure regulation. Journal of Accounting and Economics, v. 3, n. 2, p. 113-127, 1981. https://doi.org/10.1016/01654101(81)90009-4

DELOITTE, C. G. C. Guia prático para os Comitês de Auditoria das empresas brasileiras Da visão à operação. Reino Unido: Deloitte. 2013

FAUZI, F; LOCKE, S. Board structure, ownership structure and firm performance: A study of New Zealand listed-firms. Asian Academy of Management Journal of Accounting of Finance, v. 8, n 2, p. 43-67, 2012. http://hdl.handle.net/10289/7793

FURUTA, F. A relação das características das empresas com a adoção do Comitê de Auditoria X Conselho Fiscal adaptado. 2010. 2010. Tese de Doutorado. Tese (Doutorado em Ciências Contábeis) -Universidade de São Paulo, São Paulo, SP, Brasil.

FURUTA, F.; SANTOS, A. Comitê de Auditoria versus Conselho Fiscal Adaptado: a visão dos analistas de mercado e dos executivos das empresas que possuem ADRs. Revista Contabilidade \& Finanças, v. 21, n. 53, p. 1-23, 2010.

GAZLEY, B.; CHANG, W. K.; BINGHAM, L. B. Board diversity, stakeholder representation, and collaborative performance in community mediation centers. Public Administration Review, v. 70, n. 4, p. 610-620, 2010. doi:10.1111/j.1540-6210.2010.02182.x

GROSVOLD, J. Where are all the women? Institutional context and the prevalence of women on the corporate board of directors. Business \& Society. 2011.

DOI: https://doi.org/10.1177/0007650311408791

HOPE, O.; LANGLI, J. C. Auditor independence in a private firm and low litigation risk setting. The Accounting Review, v. 85, n. 2, p. 573-605, 2010.

https://doi.org/10.2308/accr.2010.85.2.573 
HOSSAIN, M. A.; TAYLOR, P. J. An examination of audit delay: Evidence from Pakistan. Unpublished draft. Available on-line, 1998.

HUANG, T.; HUANG, H.; LEE, C. Corporate executive's gender and audit fees. Managerial Auditing Journal, v. 29, n. 6, p. 527-547, 2014. https://doi.org/10.1108/MAJ-03-2013-0837

IBGC - Instituto Brasileiro de Governança Corporativa. Código das melhores práticas de governança corporativa. Disponível em: $<$ http://www.ibgc.org.br/CodigoMelhoresPraticas $>$. Acesso em: 05 jul.2015.

IBGC - Instituto Brasileiro de Governança Corporativa. Código das melhores práticas de governança corporativa. Disponível em: $<\mathrm{http} / /$ www.ibgc.org.br/inter.php?id=18095 $>$. Acesso em: 01 fev.2016. 2016a

IBGC - Instituto Brasileiro de Governança Corporativa. Código das melhores práticas de governança corporativa. 4 ed. São Paulo. 2009a

IBGC - Instituto Brasileiro de Governança Corporativa. Guia de orientações para melhores Práticas de comitês de auditoria. 7 ed. São Paulo, 2009b.

IBGC - Instituto Brasileiro de Governança Corporativa. Guia de orientações para melhores Práticas de comitês de auditoria. Disponível em

$<$ http://www.ibgc.org.br/userfiles/files/Politica\%20de\%20Representacao\%20do\%20IBGC.pdf $>$. Acesso em: 02 fev. 2016. 2016b.

IKA, S. R.; GHAZALI, N. A M. Audit committee effectiveness and timeliness of reporting: Indonesian evidence. Managerial Auditing Journal, v. 27, n. 4, p. 403-424, 2012.

Instituto Brasileiro de Governança Corporativa. Guia de orientações para melhores práticas de comitês de auditoria. (7a ed). São Paulo. 2009b

IRELAND, J. C. An empirical investigation of determinants of audit reports in the UK. Journal of Business Finance \& Accounting, v. 30, n. 7-8, p. 975-1016, 2003. DOI: 10.1111/14685957.05417

ITO, E. Y. H.; NIYAMA, J. K.; MENDES, P. C. M. Controle de Qualidade dos Serviços de Auditoria Independente: Um Estudo Comparativo entre as Normas Brasileiras e as Normas Internacionais. Contabilidade, Gestão e Governança, v. 11, n. 1-2, 2009.

JOHNSON, L. E.; DAVIES, S. P.; FREEMAN, R. J. The effect of seasonal variations in auditor workload on local government audit fees and audit delay. Journal of Accounting and Public Policy, v. 21, n. 4, p. 395-422, 2003. https://doi.org/10.1016/S0278-4254(02)00068-6

KALLEBERG, A. L.; LEICHT, K. T. Gender and organizational performance: Determinants of small business survival and success. Academy of management journal, v. 34, n. 1, p. 136-161, 1991.

KANG, H.; CHENG, M.; GRAY, S. J. Corporate governance and board composition: Diversity and independence of Australian boards. Corporate Governance: An International Review, v. 15, n. 2, p. 194-207, 2007. DOI: 10.1111/j.1467-8683.2007.00554.x 
KENT, P.; ROUTLEDGE, J.; STEWART, J. Innate and discretionary accruals quality and corporate governance. Accounting \& Finance, v. 50, n. 1, p. 171-195, 2010. DOI:

10.1111/j.1467-629X.2009.00321.X

KRISHNAN, J.; YANG, J. S. Recent trends in audit report and earnings announcement lags. Accounting Horizons, v. 23, n. 3, p. 265-288, 2009.

https://doi.org/10.2308/acch.2009.23.3.265

LEHN, K. M.; PATRO, S.; ZHAO, M. Determinants of the Size and Composition of US Corporate Boards: 1935-2000. Financial Management, v. 38, n. 4, p. 747-780, 2009. DOI: 10.1111/j.1755-053X.2009.01055.x

LEVENTIS, S.; CARAMANIS, C. Determinants of audit time as a proxy of audit quality. Managerial Auditing Journal, v. 20, n. 5, p. 460-478, 2005.

https://doi.org/10.1108/02686900510598821

LEVRAU, A.; BERGHE, L. A. A. V. D. Corporate governance and Board Effectiveness: beyond formalism. ICFAI Journal of Corporate Governance, v. 6, n. 4, p. 58-85, 2007.

LOPES, A. B.; WALKER, M. Firm-level incentives and the informativeness of accounting reports: an experiment in Brazil. Available at SSRN 1095781, 2008.

https://ssrn.com/abstract=1095781 or http://dx.doi.org/10.2139/ssrn.1095781

LOW, D. CM; ROBERTS, H.; WHITING, R. H. Board gender diversity and firm performance: Empirical evidence from Hong Kong, South Korea, Malaysia, and Singapore. Pacific-Basin Finance Journal, 2015. https://doi.org/10.1016/j.pacfin.2015.02.008

MARTINEZ, A. L. Quando o conselho de administração e a auditoria evitam o gerenciamento de resultados? Evidências empíricas para empresas brasileiras. RIC-Revista de Informação Contábil, ISSN: 1982-3967, v. 4, n. 1, p. 76-93, 2010.

MONTENEGRO, T. M.; BRAS, F. A. Audit Quality: Does Gender Composition of Audit Firms Matter? REFC-Spanish Journal of Finance and Accounting, v. 44, n. 3, p.264-297, 2015. http://dx.doi.org/10.1080/02102412.2015.1035578

NAZRI, S. N. F. S. M.; SMITH, M.; ISMAIL, Z. The impact of ethnicity on auditor choice: Malaysian evidence. Asian Review of Accounting, v. 20, n. 3, p. 198-221, 2012. https://doi.org/10.1108/13217341211263265

NG, P. PH; TAI, B. YK. An empirical examination of the determinants of audit delay in Hong Kong. The British Accounting Review, v. 26, n. 1, p. 43-59, 1994.

https://doi.org/10.1006/bare.1994.1005

OLIVEIRA, C. A participação feminina nos conselhos de administração e o desempenho corporativo: um estudo sobre as empresas listadas na BM\&FBOVESPA de 2002 a 2011.75 p. 2013. Dissertação. UNISINOS - Universidade do Vale do Rio dos Sinos, São Leopoldo. 2013

PEREIRA, A. N.; COSTA, F. M. Determinantes do atraso de auditoria externa (Audit Delay) em companhias brasileiras. In: Encontro da Associação Nacional de Programas de Pós-Graduação em Administração (ENANPAD), 36. Rio de Janeiro (RJ). Anais... Rio de Janeiro: ANPAD. 2012 
PEREIRA, A. N.; COSTA, F. M. Determinantes do atraso em auditoria externa (audit delay) em companhias brasileiras. 2011. Tese de Doutorado. Dissertação de Mestrado Profissional em Ciências Contábeis. Fundação Instituto Capixaba de Pesquisas em Contabilidade, Economia e Finanças, Vitória-ES-Brasil.

PRICEWATERHOUSECOOPERS - Brasil. Comitês de auditoria no Brasil: Melhores práticas de governança corporativa, o desafio continua. Brasil: Pwc. 2007

ROST, K.; OSTERLOH, M. Management fashion pay-for-performance for CEOs. Schmalenbach Business Review, v. 61, p. 119-149, 2009. https://ssrn.com/abstract=1406928

SHARMA, V.; NAIKER, V.; LEE, B. Determinants of audit committee meeting frequency: Evidence from a voluntary governance system. Accounting Horizons, v. 23, n. 3, p. 245-263, 2009. https://doi.org/10.2308/acch.2009.23.3.245

SILVA, K. L. et al. A Implementação dos Controles Internos e do Comitê de Auditoria Segundo a Lei SOX: o Caso Petrobras. Contabilidade Vista \& Revista, v. 20, n. 3, p. 39-63, 2009.

SINGH, V.; VINNICOMBE, S. Why so few women directors in top UK boardrooms? Evidence and theoretical explanations. Corporate Governance: An International Review, v. 12, n. 4, p. 479-488, 2004. doi:10.1111/j.1467-8683.2004.00388.x

SOLTANI, B. Timeliness of corporate and audit reports: Some empirical evidence in the French context. The International Journal of Accounting, v. 37, n. 2, p. 215-246, 2002. https://doi.org/10.1016/S0020-7063(02)00152-8

SULTANA, N. et al. Audit Committee Characteristics and Audit Report Lag. International Journal of Auditing, 2015. doi:10.1111/ijau.12033

TANG, X.; DU, J.; HOU, Q. The effectiveness of the mandatory disclosure of independent directors' opinions: Empirical evidence from China. Journal of Accounting and Public Policy, v. 32, n. 3, p. 89-125, 2013. https://doi.org/10.1016/j.jaccpubpol.2013.02.006

TEIXEIRA, S. C. A relação entre a adoção de práticas recomendadas de Governança Corporativa e o nível de evidenciação. 2010. Tese de Doutorado. Universidade de São Paulo.

THIRUVADI, S. Gender differences and audit committee diligence. Gender in Management: An International Journal, v. 27, n. 6, p. 366-379, 2012. https://doi.org/10.1108/17542411211269310

THIRUVADI, S.; HUANG, H. Audit committee gender differences and earnings management. Gender in Management: An International Journal, v. 26, n. 7, p. 483-498, 2011. https://doi.org/10.1108/17542411111175469

WALLER, W. Accidental Veblenian, intentional institutionalist, and inevitable feminist. Journal of Economic Issues, p. 326-334, 2005. http://dx.doi.org/10.1080/00213624.2005.11506809

XIE, B.; DAVIDSON, W. N.; DADALT, P. J. Earnings management and corporate governance: the role of the board and the audit committee. Journal of corporate finance, v. 9, n. 3, p. 295316, 2003. https://doi.org/10.1016/S0929-1199(02)00006-8 
YANG, J S.; KRISHNAN, J. Audit committees and quarterly earnings management. International Journal of Auditing, v. 9, n. 3, p. 201-219, 2005. DOI: 10.1111/j.10991123.2005.00278.x

YI, A. Mind the gap: Half of Asia's boards have no women, a risky position for governance and growth. Korn/Ferry Institute. 2011.

ZHANG, Y.; ZHOU, J.; ZHOU, N. Audit committee quality, auditor independence, and internal control weaknesses. Journal of accounting and public policy, v. 26, n. 3, p. 300-327, 2007. https://doi.org/10.1016/j.jaccpubpol.2007.03.001 